\title{
Experimental Study on Uniaxial Compressive Strength of Cement Mortar with Recycled Lightweight Aggregate
}

\author{
Xiang-Gang ZHANG ${ }^{1,2, a,{ }^{*},}$, Fang WANG ${ }_{1,3, d}^{2, b}$, Peng WANG ${ }^{1,3, c}$, Sheng-Bo ZHOU \\ ${ }^{1}$ Guangxi Key Lab of Road structure and materials, Nanning, China \\ ${ }^{2}$ School of Civil Engineering, Henan Polytechnic University, Jiaozuo, China \\ ${ }^{3}$ Guangxi Transportation Research Institute, Nanning, China \\ axgzhang@hpu.edu.cn, b418824997@qq.com, c176356818@qq.com, d187298821@qq.com, \\ ${ }^{*}$ Corresponding author
}

\begin{abstract}
Keywords: Recycled cement mortar, Replacement rate, Cube compressive strength, Recycled lightweight aggregate
\end{abstract}

\begin{abstract}
In order to study uniaxial compressive strength of the recycled lightweight aggregate cement mortar test cubes, replacement rate of recycled lightweight aggregate was selected as variables factors, uniaxial compression test of cement mortar was carried out with the use of five different recycled lightweight aggregate replacement rates (respectively 100\%, 75\%, 50\%, 25\%, $0 \%$ ). The destruction process and failure mode was observed, the ultimate compressive strength value of test cubes was recorded, the cube compressive strength-recycled lightweight aggregate replacement rate curve was obtained, it analyzes the impact of factor on compressive strength test cubes. The results showed when the recycled lightweight aggregate replacement rate of lightweight aggregate cement mortar is $0 \%$, its compressive strength is the highest; when the recycled lightweight aggregate replacement rate of lightweight aggregate cement mortar is $75 \%$, its compressive strength is the ideal state; failure mode is similar to ordinary cement mortar, it occurred at the interface between lightweight aggregate concrete and cementations materials.
\end{abstract}

\section{Introduction}

According to statistics [1], at present, the garbage of our country's construction has occupied the city garbage $30 \% \sim 40 \%$, of which the $50 \% \sim 60 \%$ is concrete. In view of the increasing harm of waste concrete, in order to protect the environment, conserve resources, and optimize the allocation of resources, it is urgent to use construction waste [2]. Recycled cement mortar refers to the aggregate replacement of cement mortar in the waste concrete by the crushing, screening, cleaning and other steps made of recycled materials. Study recycled cement mortar is expected to be able to realize recycling of resources, reduce garbage of construction $[3,4]$. The test required for regeneration lightweight aggregate is made of waste concrete after crushing processing. Made of crushing processing procedures such as recycled aggregate instead of natural aggregate can reduce the construction for the consumption of natural aggregate, alleviate the pressure of increasingly scarce natural aggregate, social, economic and environmental benefits are more obvious [5].

$\mathrm{Xu}$ Ming, Wang Tao. et al [6] have studied the stress-strain relationship of the uniaxial compressive of recycled mortar specimens after high temperature, and the stress-strain curve is obtained. The results show that: with the increase of the replacement rate of recycled aggregate, the stress-strain curve peak stress decreases. In order to reveal at room temperature under different replacement rate and dry apparent density effects on the regeneration of lightweight aggregate cement mortar uniaxial compressive strength, this paper selects $100 \%, 75 \%, 50 \%, 25 \%, 0 \%$ five different replacement rates were designed into five groups of recycled cement mortar, compare the mechanical properties of mortar and ordinary cement, analysis of different replacement rate for recycled effect of lightweight aggregate cement mortar cube compressive strength. In order to get the relationship curve between the compressive strength and the replacement rate, the compressive 
strength-dry density curve, so as to lay the foundation for exploring the strength index and the higher strength of the cement mortar.

\section{Test Overvie w}

\subsection{Raw Materials}

Cement: The P.O 42.5 cement produced by the Jiaozuo limited company of sturdy cement was adopted;

Natural aggregate: Natural aggregate is the natural river sand, the maximum particle size is $5 \mathrm{~mm}$. The bulk density is $1321 \mathrm{~kg} / \mathrm{m} 3$, as shown in Figure 1 (a);

Recycled aggregate: recycled light aggregate as shown in Figure 1 (b) was from the test cube lightweight aggregate concrete test block after crushing, screening, cleaning, drying in Henan Polytechnic University structure hall, and the bulk density is $623 \mathrm{~kg} / \mathrm{m}^{3}$;

Mixing and curing water: ordinary tap water.

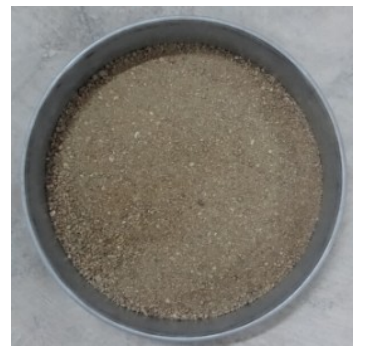

(a) Natural aggregate

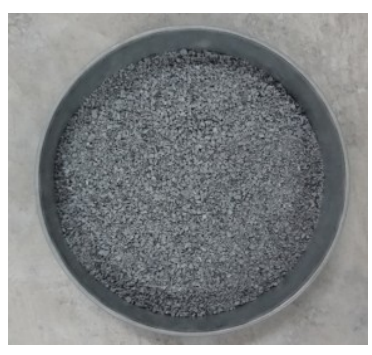

(b) Recycled aggregates

Fig.1 The aggregate of concrete

\subsection{Mix Proportion}

Five different replacement rates of the recycled light aggregate to cement mortar test block was selected, the replacement rate of $0 \%$ of the ordinary mortar test block was selected as the benchmark test block, $25 \%, 50 \%, 75 \%, 100 \%$ and so on four kinds of different replacement rate test block as a contrast test block, replacement rate according to the volume of replacement. The test block strength grade of recycled lightweight aggregate cement mortar is M15, referring JGJ T98-2010“Mortar Mix design procedures" in mix design, under different replacement rate, the mixture rate of recycled lightweight aggregate cement mortar is adjusted accordingly. Test mix was shown in table 1.

Tab.1 Proportion of recycled cement mortar

\begin{tabular}{ccccc}
\hline \multirow{2}{*}{ Replacement rate $(\%)$} & Cement $\left(\mathrm{kg} / \mathrm{m}^{3}\right)$ & Water $\left(\mathrm{kg} / \mathrm{m}^{3}\right)$ & \multicolumn{2}{c}{ Aggregate $\left(\mathrm{kg} / \mathrm{m}^{3}\right)$} \\
\cline { 3 - 5 } & 370.0 & 310.0 & Light sand & Ordinary sand \\
\hline 0 & 370.0 & 310.0 & 155.8 & 1321.0 \\
50 & 370.0 & 310.0 & 311.5 & 990.8 \\
75 & 370.0 & 310.0 & 467.3 & 660.5 \\
100 & 370.0 & 310.0 & 623.0 & 330.3 \\
\hline
\end{tabular}

\subsection{Block Production and Test Method}

Standard design of $70.7 \mathrm{~mm} \times 70.7 \mathrm{~mm} \times 70.7 \mathrm{~mm}$ size for test block was used. Each group plans to take 3 test blocks. According to the JGJ-T70-2009 "the mortar test method" was regenerated light aggregate cement mortar mixture mixing, the specimen in the $20 \pm 5^{\circ} \mathrm{C}$ temperature conditions under maintenance 24 hours after form removal, after curing to $28 \mathrm{~d}$ in standard curing condition, then 
carry on the load, measured its compressive strength. Compressive strength test content reference JGJ/T70-2009 "building mortar basic performance test method standard", when the three values of the maximum value and the minimum value in a difference value and the median value more than $15 \%$ of the median value, the maximum and minimum truncation together, take the middle value as the value of the compressive strength of the specimen; If the difference between the two values and the middle value is more than $15 \%$ of the middle value, the test results of the test piece is invalid, the average value of the 1.3 times of the arithmetic mean of the 3 test blocks is used as the average value of the compressive strength of the test block. Loading device for the SYE-2000 type pressure testing machine, as shown in Figure 2, the loading rate of $9 \mathrm{kN} / \mathrm{s}$, the maximum range of $2000 \mathrm{kN}$.

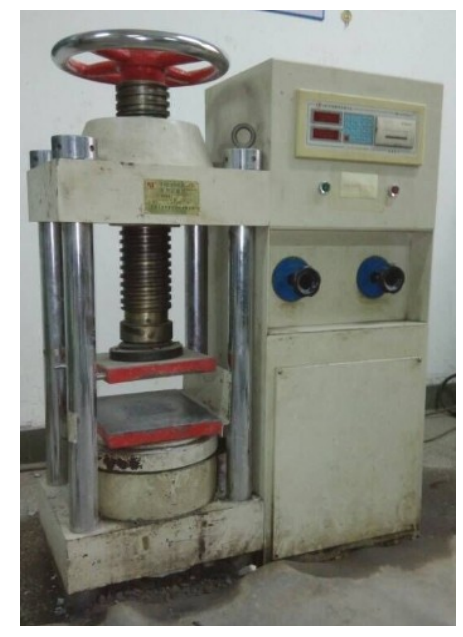

Fig.2 Loading device

\section{Test results and Analysis}

\subsection{Failure Process and Failure Mode of Test Block}

The failure process of recycled lightweight aggregate cement mortar and common test block is quite similar in general. Initial stage of loading, the cement mortar test block found no obvious cracks; But with the increase of load, recycled lightweight aggregate and cement mortar test block internal interactions increase, gradually manifested in the side surface of the test block, especially the middle position of the side surface began along the vertical direction where some micro-cracks. Gradually increase the load will cause initial cracks gradually become larger, to the two direction extension, when the load is increased to a limit load and cement mortar test block to reach the limit state of bearing capacity, lateral surface of the cement mortar began to muster, fall off, the final destruction.

The destruction form of recycled lightweight aggregate cement mortar is shown in Figure 3. It can be seen that the damage forms of recycled lightweight aggregate cement mortar and common test block are basically similar, and the damage occurs at the interface of cement mortar cement mortar. So the compressive strength of recycled lightweight aggregate cement mortar is influenced by the bond strength of recycled aggregate and cement colloid.
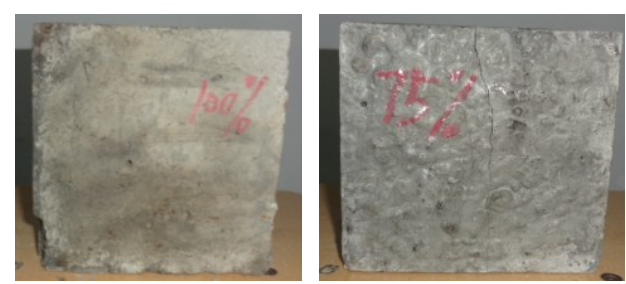

(a) Replace rate $100 \%$ (b) Replace rate $75 \%$
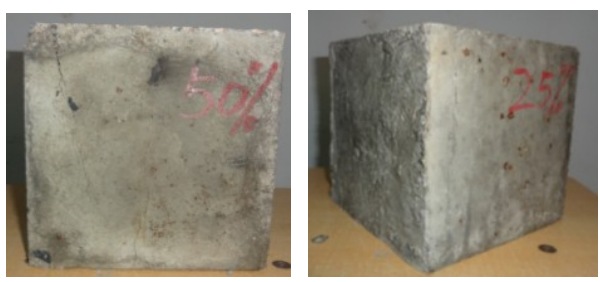

(d) Replace rate $25 \%$ (e) Replace rate $0 \%$

Fig.3 Failure modes 


\subsection{Cubic Compressive Strength}

The cubic compressive strength of recycled lightweight aggregate cement mortar under different replacement rates were calculated according to the test results of the critical load under different replacement rates. As shown in table 2, it can be seen that different replacement rates regeneration lightweight aggregate and cement mortar test block cube compressive strength have reached the requirements of design strength grade, the compressive strength of recycled lightweight aggregate cement mortar is affected by the change of the replacement rate of recycled lightweight aggregate obviously. The compressive strength-replacement rate curve is not linear, as shown in Figure 4.

Tab.2 The recycled cement mortar compressive strength (MPa)

\begin{tabular}{lllll}
\hline Replacement rate(\%) & Sample 1 & Sample 2 & Sample 3 & The average \\
\hline 100 & 12.69 & 13.79 & 11.37 & 16.41 \\
75 & 13.79 & 13.48 & 15.63 & 18.59 \\
50 & 22.49 & 13.30 & 13.55 & 17.62 \\
25 & 14.96 & 13.86 & 12.45 & 17.89 \\
0 & 14.92 & 15.86 & 13.28 & 19.10
\end{tabular}

Note: the average value in the table are calculated according to the arithmetic mean value of 1.3 times.

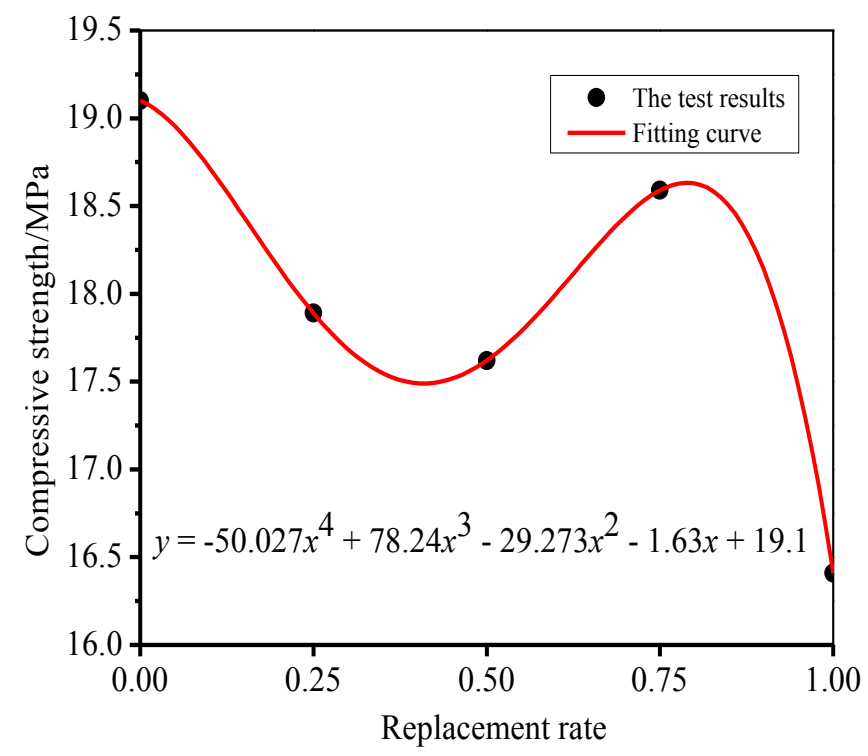

Fig.4 Compressive strength and replace rate curve

Figure 4 shows that the compressive strength of recycled cement mortar and replaced by a mathematical model for the expression rate:

$$
y=\mathrm{ax}+\mathrm{b} x^{3}+\mathrm{cx} x^{2}+\mathrm{d} x+\mathrm{e}
$$

Which a, b, c, d and e were control parameters, it can be obtained by fitting. a value is $-50.027, \mathrm{~b}$ value is 78.24 , c value is -29.273 , d value is -1.63 , e value is 19.1 , the fitting accuracy is 1 .

When the replacement rate is $0 \%$, the compressive strength of recycled lightweight aggregate cement mortar is the highest. In the case of any replacement rate of recycled light aggregate, the compressive strength of the test block is lower than that of the natural cement mortar. With the increase of the replacement rate, the compressive strength of the cube specimen decreases and then 
increases and then decreases. When the replacement rate is $75 \%$, the intensity reaches the peak value, which belongs to the ideal state. It can be considered that the $75 \%$ is the optimal replacement rate, at this time, the compressive strength can reach $97.33 \%$ of the compressive strength of the cement mortar.

\section{Influencing Factors Analysis}

As seen from Figure 5, with the increase of recycled lightweight aggregate replacement rate, the change tendency of the compressive strength of the mortar test block is first decreased and increased and then decreased. Its change rates were $6.33 \%, 1.5 \%, 5.5 \%, 11.7 \%$. The reason why this is the case, the reason is: in the process of breaking the waste concrete, regeneration lightweight aggregate internal regeneration often more or less have some fine pores and micro-cracks initial damage, with the increase of the replacement rate, the recycled lightweight aggregate will increase. The initial damage of mortar test block is more and more serious. Initial damage will have an significant adverse effects on the compressive strength of cement mortar, the influence degree is closely related to the initial damage degree of mortar test block. While with the increase of the replacement rate, water to cement rate of mortar test block would be lower. The initial da mage and water-cement rate two factors comprehensive cross influence the compressive strength of recycled cement mortar. When the replacement rate is $75 \%$, the initialdamage and water binder ratio tend to be balanced. So when the replacement rate of recycled light aggregate cement mortar is $75 \%$, the compressive strength of mortar test block is optimal. It can achieve the natural test block compressive strength of $97.33 \%$.

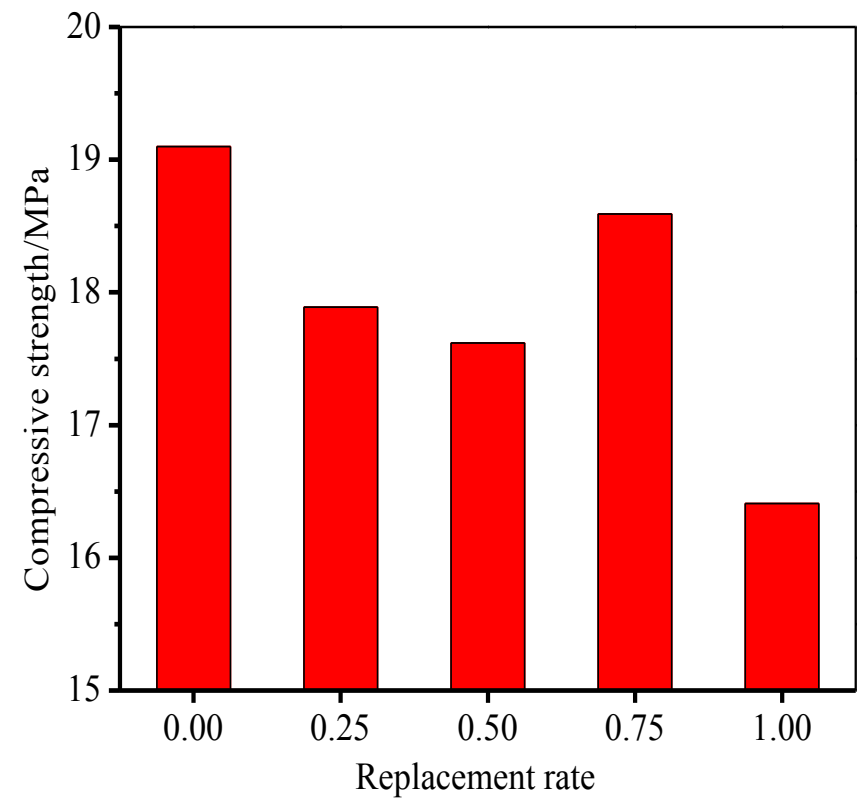

Fig.5 Cube compressive strength under different replacement rates

\section{Conclusion}

Failure process and failure mode of recycled lightweight aggregate cement mortar test block are closer to the ordinary cement mortar, its destruction occurs at the interface between the lightweight aggregate and cement cementitious materials; when the recycled lightweight aggregate of cement mortar lightweight aggregate replacement rate is $75 \%$, the initial damage and water-cement ratio tends to be balanced, its compressive strength is the ideal state, $75 \%$ can be considered as the optimal replacement rate; recycled lightweight aggregate cement mortar test block can achieve maximum compressive strength of natural cement mortar compressive strength test block $97.33 \%$. 


\section{References}

[1] Zhao Jun, Liu Qiuxia, Lin Liqing, et al. Journal of Central South University (Natural Science), 2013, 44(4): 1297-1304. (in Chinese)

[2] Zhang Xianggang, Chen Zongping, Xue Jianyang. Silicate Bulletin, 2015, 34(6): 1685-1688. (in Chinese)

[3] Ma Jing, Wang Zhenbo. Concrete and Cement Products, 2012(3): 18-21. (in Chinese)

[4] Monalisa B, Bhattacharyya S K, Minocha A K, et al. Recycled aggregate from C\&D waste \& its use in concrete-A breakthrough towards sustainability in construction sector: A review, Construction and Building Materials, 2014, 68: 501-516.

[5] Xiao Jianzhuang. Recycled Concrete. Beijing, 2008: 3-4. (in Chinese)

[6] Xu Ming, Wang Tao, Chen Zhongfan. Journal of Building Structure, 2015, 36(2): 152-154. (in Chinese) 